\title{
On the determinants of exchange rate misalignments
}

Jamel Saadaoui $^{\mathrm{a} *}$, Jacques Mazier ${ }^{\mathrm{a}}$, Nabil Aflouk ${ }^{\mathrm{a}}$

${ }^{a}$ University of Paris North, Center of Economics of Paris North, Villetaneuse, France.

*Corresponding author. E-mail: jamelsaadaoui@gmail.com

The literature on exchange rate misalignments is very extensive as well as the literature on exchange rate determinants. To our knowledge, however, no study has analysed the determinants of exchange rate misalignments. As huge capital inflows have been pouring into emerging countries since the climax of the crisis, exchange rate misalignments are becoming a crucial issue for policy makers. For a large panel of emerging and industrialized countries and over the period 1982 to 2008, we identify, empirically, the main determinants of exchange rate misalignments obtained thanks to a FEER approach (Williamson, 1994). Our analysis put forward trade openness, financial openness and regional specialization as determinant variables of exchange rate misalignments.

JEL Classification: F31; F32; O11.

Key Words: Exchange rate misalignments, trade openness, financial openness, regional specialization. 


\section{Introduction}

As noted by Feldstein (2011), some emerging countries have experienced a surge of capital inflows mainly because of favourable interest rate differentials with developed economies. This favourable interest rate differential is the outcome of economic policy lead by some developed countries in order to sustain aggregate demand after the burst of the crisis in 2008 .

In this general context, the objective of the article is to analyse the main determinants of exchange rate misalignments (ERM, hereafter) obtained by a FEER approach (Aflouk et al., 2010).

The literature on ERM is very extensive as well as the literature on exchange rate determinants. To our knowledge, however, no study has analysed the determinants of exchange rate misalignments. As huge capital inflows have been pouring into emerging countries since the climax of the crisis, exchange rate misalignments are becoming a crucial issue for policy makers. For a large panel of emerging and industrialized countries (the United States, the United-Kingdom, the Euro area, Japan, Korea, China, Brazil, India, Mexico, Argentina, Chile, Colombia, Indonesia, Malaysia, Philippines, Thailand and Uruguay) and over the period 1982-2008, we identify, empirically, the main determinants of ERM. Our analysis put forward trade openness, financial openness and regional specialization as determinant variables of ERM.

The remainder of the article is organized as follows. Section 2 describes the main characteristics of the trade model used to estimate ERM. Section 3 identifies three variables which explain the ERM in the long run. Section 4 concludes. 


\section{Trade Model}

\section{The multinational model}

The model describes the trade structure of the main countries or areas, namely, the United States, Japan, China, the Euro area, the United Kingdom and the Rest of the World using standard foreign trade equations: export and import volume equations, export and import price equations.

In this framework, the FEERs are defined as the real effective exchange rates compatible with the simultaneous realization of the internal and external equilibriums at medium term of each trading partner. The internal equilibrium means that actual output follows the potential output and the external equilibrium means that actual current account corresponds to the sustainable current account at medium term $^{1}$.

\section{The national model}

For each emerging country, except China, thanks to results of the multinational model, it is possible to estimate an equilibrium exchange rate using a foreign trade model in which the world demand and the world trade prices are exogenous. It is not necessary for a relatively small country at the world scale to use a multinational

\footnotetext{
${ }^{1}$ The model is fully described in Jeong et al. (2010). The methodology used is a synthesis of previous works on the FEER (Borowski and Couharde, 2003; Jeong and Mazier, 2003) and of the Symmetric Matrix Inversion Method (SMIM) recently proposed by Cline (2008).
} 
model to estimate equilibrium exchange rates (Jeong and Mazier, 2003). The equations specify the trade volume and price equations for a small country facing world economy. Solving this simplified model in logarithmic differential form gives $r$, the misalignment in real effective terms:

$r_{i}=\left[\frac{\left(\left(b_{i} /\left[\mu_{i} T_{i}\left(1-\sigma_{p e t x i}-\sigma_{x i}\right)\right]\right)+\eta m_{i} d i_{i}-\eta x_{i} d_{i}^{*}\right)}{\left(\left(1-\alpha x_{i}\right) \varepsilon x_{i}+\varepsilon m_{i} \alpha m_{i}+\alpha x_{i}-\alpha m_{i}\right)}\right]$

Where $b$ is the difference between the observed current account and the equilibrium one, as percentage of GDP, $d^{*}$ is the world demand in volume and $d i$ is the internal demand in volume, written in logaritmic differential compared with the equilibrium, $\sigma_{p e t x}=E P_{p e t} M_{p e t} / P X X$ is the ratio of net oil imports on nonoil exports and $\sigma_{x}=$ $i E F / P X X$ is the ratio of foreign debt service on nonoil exports, $\mu$ the openness ratio and $T$ the ratio of export to import.

\section{Determinants of ERM}

\section{Panel unit root tests}

In this sub-section, we implement various unit root tests in order to determine the order of integration of the absolute value of the ERM (aerm) and its explanatory variables, namely, the trade openness ratio (open) measured as the half-sum of export and import in percentage of GDP, the relative financial openness indicator (rkaopen) based on a de jure measure of capital account openness (the Chinn-Ito index, 2008) 
and the regional specialization indicator (xreg) measured as the share of exports towards the regional area (East Asia, South America and North America) in percentage of total exports.

[Insert Table 1 about here]

As we can see in Table 1, all the series are nonstationary I(1) series except aerm. As a series is $\mathrm{I}(1)$ if it achieves stationarity after first differencing. The series of ERM measured in absolute value, aerm, is a stationary series.

\section{Cointegration tests}

The next step will consist to test if there is a long run relationship between the absolute value of the ERM and its determinants (that is the residuals are stationary). If a long run relationship exists then we can estimate this long run relationship thanks to the Pooled Mean Group (PMG) estimator introduced by Pesaran et al. (1999).

As we can see in Table 2, the results of Westerlund's cointegration tests (2007) indicate clearly that the aerm variable is cointegrated with its determinants at the 1 per cent level. In these tests, the existence of a negative and significant error correction term is taken as proof for cointegration. In case of cross section dependencies between members of the panel, critical values need to be obtained through bootstrapping.

[Insert Table 2 about here] 
As the variables are cointegrated, we can estimate the long relationship thanks to the PMG estimator. Since the PMG estimator imposes long-run coefficients to be constant for all individuals, while it allows short run heterogeneity, the error correction model associated with the ARDL $(1,1,1,1)$ specification yields:

$$
\begin{aligned}
& \operatorname{\Delta aerm}_{i, t}=\phi\left(\text { aerm }_{i, t-1}-\theta_{0}-\theta_{1} \text { open }_{i, t}-\theta_{2} \text { rkaopen }_{i, t}-\theta_{3} \text { xreg }_{i, t}\right) \\
& -\delta_{2 i} \Delta_{\text {open }_{i, t}}-\delta_{4 i} \Delta \text { rkaopen }_{i, t}-\delta_{6 i} \Delta x r e g_{i, t}+\varepsilon_{i, t}
\end{aligned}
$$

As we can see in Table 3, all the variables are significant and correctly signed. Higher trade openness (open increases) increases the impact of a variation of price competitiveness on current account. Consequently, a smaller variation of exchange rate is necessary to reach the external equilibrium, which implies smaller misalignments. Stronger regional (xreg increases) integration implies more price competition, which limits misalignments. Higher financial openness (rkaopen increases) facilitates monetary adjustments, which reduces exchange rates misalignments, while capital controls have the opposite effect. A negative relation is therefore expected between the financial openness indicator and misalignment. The Hausman test confirms the long run homogeneity of the coefficients.

[Insert Table 3 about here] 


\section{Conclusion}

In a context of increasing movements of capital flows observed since the climax of the crisis (especially capital inflows towards emerging countries), the objective of the article was to analyse the main determinants of ERM obtained by a FEER approach. For a large panel of emerging and industrialized countries and over the period 1982 to 2008, we identify, empirically, the main determinants of ERM. Our analysis put forward trade openness, financial openness and regional specialization as determinant variables of ERM.

Our results show that a reduction of misalignments could be obtained by gradual increase of capital account openness especially for South East Asian countries that run large undervaluation as the trade openness ratio and regional specialization are more structural variables. These results are consistent with those of Saadaoui (2011) in which a gradual openness of capital account should help to reduce the large current account surpluses of South-East Asian countries in the medium run (through upward pressures on domestic investment rates). 


\section{References}

Aflouk, N., Jeong, S.-E., Mazier, J., Saadaoui, J. (2010). Exchange Rate Misalignments and International Imbalances: a FEER Approach for Emerging Countries. Économie Internationale / International Economics, 124, 31-74.

Borowski, D., Couharde, C. (2003). The Exchange Rate Macroeconomic Balance Approach: New Methodology and Results for the Euro, the Dollar, the Yen and the Pound Sterling. Open Economies Review, 14, 169-190.

Chinn, M.D., Ito, H. (2008). Global Current Account Imbalances: American Fiscal Policy versus East Asian Savings. Review of International Economics, 16, 479-498.

Cline, W. R. (2008). Estimating Consistent Fundamental Equilibrium Exchange Rates. Working Paper No. 08-6, Peterson Institute for International Economics.

Feldstein, M. S. (2011). The Role of Currency Realignments in Eliminating the US and China Current Account Imbalances. Working Paper No. 16674, NBER.

Jeong, S.-E., Mazier, J. (2003). Exchange Rate Regimes and Equilibrium Exchange Rates in East Asia. Revue Économique, 54, 1161-1182.

Jeong, S.-E., Mazier, J., Saadaoui, J. (2010). Exchange rate misalignments at world and European levels: A FEER approach. Économie Internationale / International Economics, 121, 25-58.

Pesaran, M. H. (2007). A simple unit root test in the presence of cross section dependence. Journal of Applied Econometrics, 22, 265-312. 
Persyn, D., Westerlund, J. (2008). Error correction based cointegration tests for panel data. Stata Journal, 8, 232-241.

Pesaran, M. H., Shin Y., Smith R. P. (1999). Pooled mean group estimation of dynamic heterogeneous panels. Journal of the American Statistical Association, 94, $621-634$.

Saadaoui, J. (2011). Global imbalances and capital account openness: an empirical analysis, CEPN Working Paper No. 2011-18, University of Paris North.

Westerlund, J. (2007). Testing for error correction in panel data. Oxford Bulletin of Economics and Statistics, 69, 709-748. 
Table 1. Panel unit root tests

\begin{tabular}{lll}
\hline CADF & Level & First Difference \\
\hline \multirow{2}{*}{ aerm } & $-2.670 * * *$ & $-11.670 * * *$ \\
& $(0.004)$ & $(0.000)$ \\
\hline \multirow{2}{*}{ open } & 3.528 & $-5.059 * * *$ \\
& $(1.000)$ & $(0.000)$ \\
\multirow{2}{*}{ rkaopen } & 2.807 & $-4.604 * * *$ \\
& $(0.997)$ & $(0.000)$ \\
xreg & -0.257 & $-6.220 * * *$ \\
& $(0.398)$ & $(0.000)$ \\
\hline
\end{tabular}

Source: authors' calculations.

Notes: The $p$-values are in parentheses. The symbol *** indicates statistical stationarity at the 1 per cent level. 
Table 2. Panel cointegration tests

\begin{tabular}{|c|c|}
\hline Westerlund (2007) & aerm, open, rkaopen, xreg \\
\hline$G \tau$ & $\begin{array}{l}-7.863 * * * \\
(0.000)\end{array}$ \\
\hline$G \alpha$ & $\begin{array}{l}-3.334 * * * \\
(0.000)\end{array}$ \\
\hline$P \tau$ & $\begin{array}{l}-5.398 * * * \\
(0.000)\end{array}$ \\
\hline$P \alpha$ & $\begin{array}{l}-4.809 * * * \\
(0.000)\end{array}$ \\
\hline
\end{tabular}

Source: authors' calculations.

Notes: The symbol $* * *$ indicates statistical significance at the 1 per cent level. The $p$-value for cointegration tests are based on bootstrap methods, where 800 replications are used. See Persyn and Westerlund (2008) for the details. 
Table 3. Long run determinants of ERM

\begin{tabular}{lll}
\hline$P M G^{1}$ & Long Run Coefficients $(\theta)$ & -value \\
\hline open & $-0.311^{* * *}$ & 0.000 \\
\hline rkaopen & $-0.022^{* * *}$ & 0.005 \\
\hline xreg & $-0.331 * * *$ & 0.001 \\
\hline $\begin{array}{l}\text { Error-corrections } \\
\text { coefficient }(\phi)\end{array}$ & $-0.578^{* * *}$ & 0.000 \\
\hline $\begin{array}{l}\text { Hausman test } \\
\text { Cross-section included }\end{array}$ & 2.740 & 0.430 \\
\hline Number of Observations & 442 & \\
\hline Sourc: atho' clitions
\end{tabular}

Source: authors' calculations

Notes: (1) Pooled Mean Group estimator. The symbol *** indicates statistical significance at the 1 per cent level.

The null hypothesis in the Hausman test is homogeneity of the long run coefficient in the PMG estimation. 